\title{
POLÍTICAS CURRICULARES EM PORTUGAL NA SEGUNDA DÉCADA DO SÉCULO XXI: entre lógicas de regulação compósitas e deslocamentos da ação educativa para o coletivo da escola
}

\author{
Preciosa Fernandes \\ Universidade do Porto - U. PORTO, Portugal \\ Paulo Marinho \\ Universidade do Porto - U. PORTO, Portugal
}

\begin{abstract}
Resumo
O artigo analisa a centralidade do professor expressa nas propostas políticas de autonomia e flexibilidade curricular e de uma Educação Inclusiva, em curso desde 2017/2018 em Portugal, na sua relação com possíveis lógicas de regulação. Metodologicamente centrado na análise destas políticas, o presente artigo tem como objetivo desocultar e problematizar, a centralidade que nelas "ocupam” os professores. Conclui-se que sendo os discursos mais direcionados para a escola, eles denunciam um deslocamento do ônus da responsabilidade da decisão curricular do individual (professor) para o coletivo (escola) evidenciando, ao mesmo tempo, uma lógica de regulação híbrida/compósita do trabalho dos professores, assente em ordens centralizadas e simultaneamente localizadas.
\end{abstract}

Palavras-chave: Políticas curriculares; Educação Inclusiva; Autonomia e Flexibilidade curricular; Regulação; Profissional Híbrido.

\begin{abstract}
The article analyzes the centrality of the teacher expressed in the political proposals for curricular autonomy and flexibility and for an Inclusive Education, underway since 2017/2018 in Portugal, in their relationship with possible logics of regulation. Methodologically centered on the analysis of these policies, this article aims to unveil and problematize the centrality that teachers "occupy" in them. It is concluded that, as the discourses are more directed to the school, they denounce a shift in the burden of responsibility for the curricular decision from the individual (teacher) to the collective (school) showing, at the same time, a logic of hybrid / composite work regulation teachers, based on centralized and demanded orders.
\end{abstract}

Keywords: Curriculum policies; Inclusive education; Curricular autonomy and flexibility; Regulation; Hybrid Professional. 


\section{Introdução}

Em linha com orientações internacionais anteriores, (UNESCO, 2004, 2008, 2009, 2015, 2017), a Agenda Global para a Educação 2030 (ONU, 2018) e, mais concretamente, o objetivo 4 "assegurar a educação inclusiva e equitativa de qualidade, e promover oportunidades de aprendizagem ao longo da vida para todos” (ONU, p.8) têm justificado a adoção de políticas fundadas no princípio de igualdade de oportunidades de sucesso para todos e numa conceção de educação inclusiva.

Estas políticas, no que à realidade portuguesa diz respeito, foram-se fazendo sentir nomeadamente com o alargamento da escolaridade obrigatória do 6. ${ }^{\circ}$ para o 9. ${ }^{\circ}$ ano, em 1986 , com a Lei de Bases do Sistema Educativo (Portugal, 1986), e para o 12. ${ }^{\circ}$ ano em 2009 (Portugal, 2009). Estes dois momentos parecem simbolizar, do ponto de vista politico, importantes marcos, representativos da procura, pelo poder político, e pelo sistema educativo, de uma educação "para todos”. Nesta trajetória, quase uma década depois, em 2017, foi lançado o Perfil do Aluno à Saída da Escolaridade Obrigatória (PASEO) homologado pelo Despacho n. ${ }^{\circ} 6478$ (Portugal, 2017) e, em 2018, as propostas de uma Educação Inclusiva (Portugal, 2018a) e de Autonomia e Flexibilidade Curricular (Portugal, 2018b). A implementação sequencial destes três documentos parece novamente evidenciar um reconhecimento político sobre a relevância de se pensar a educação como um direito de todos e o currículo como um processo que precisa ser contextualizado às realidades sociais e culturais dos alunos e aos seus interesses, ritmos e estilos de aprendizagem (Fernandes et al, 2013; Fernandes; Oliveira, 2019; Figueiredo; Leite; Fernandes, 2019). Foi no quadro da implementação simultânea daquelas propostas curriculares, e de um entendimento do papel dos professores como peças centrais para a sua efetiva concretização que se realizou a pesquisa que neste artigo se dá conta. Esta tem como objetivo analisar a centralidade dos professores nos três documentos em análise. De modo mais específico, o estudo orientou-se pelas seguintes questões: que conceção/papel de professor é expressa nessas políticas curriculares? Para que lógicas de regulação docente apontam os discursos dos textos analisados? Identificar como esses enfoques sobre a docência se articulam discursivamente nos textos analisados configura a lógica que presidiu à análise.

\section{O papel professor e sua reconfiguração num cenário de politicas hibridas}

Em espaços e tempos de globalização desenfreada, (Dale, 2008; Robertson; Dale, 2014) os discursos educacionais, neste séc. XXI, têm sido marcados por tensões decorrentes de políticas curriculares assentes quer em lógicas de regulação centralizada (Leite, 2005; Fernandes, 2011; Pacheco; Sousa, 2018;), quer em lógicas de caráter descentralista apoiadas em discursos de atribuição de maior autonomia e poder de decisão às escolas e aos professores (Afonso, 2012; Barroso, 2004; Leite; Fernandes, 2012; Lima, 2014; Marinho; Leite; Fernandes, 2019). Essas tensões têm provocado, em curtos ciclos de tempo e, por 
vezes, de forma esquizofrénica, mudanças nos modelos de organização escolar e exigido reconfigurações nos perfis de ação dos professores (Coelho, 2015).

Reconhecendo que este não é um cenário novo, Sousa (2019), sustenta que em Portugal o panorama tem configurado uma "sinfonia" de políticas de regulação da profissionalidade e da ação docente caracterizada por "[...] andamentos mais vagarosos, mais pesados ou mais leves, mais corridos, mais intensos, [...] uma sinfonia inacabada que prossegue a sua pauta” (Sousa, 2019, p. 83), sendo por vezes difícil de reconhecer o compositor. Este cenário tem sido associado à influência de uma agenda político-económica globalmente estruturada para a educação (Dale, 2008; Ball, 2001, 2003, 2014), e à pressão que exerce sobre as escolas e os professores a um exercício de controlo permanente que garanta o seu lugar no mercado (Fuller, 2018). É dentro deste racional que tem sido assinalado que as iniciativas de caráter descentralista, tendo por base um vigoroso legado político de matriz hegemónica global "[...e] assentes, muitas vezes, num discurso inovador disfarçado, acabam por se constituir apenas em 'ensaios políticos' [...] com fortes implicações nos quotidianos escolares, e nas lógicas e culturas de trabalho dos professores” (Marinho; Leite; Fernandes, 2019, p. 924). É também segundo este racional que tem sido reconhecida a importância de ser delegado aos professores o poder de agir para a mudança e para a inovação curricular, isto é, de assumirem o seu poder de agência, autoria (Morgado, 2016; Priestley; Biesta; Robinson, 2013, 2015; Marinho; Delgado, 2019) e autonomia na (re)configuração do currículo, e nas várias ações do seu trabalho, negociando a correlação de forças existentes na escola, e seu contexto (Selles; Andrade, 2016), de modo a possibilitar mudanças prepositivas de melhoria (Bolívar, 2012) organizacional. Esse parece ser o caminho, entendido como plausível para a promoção de culturas organizacionais transformacionais (Leite; Fernandes, 2010; Northouse, 2016; Bolívar, 2017). Isto é, culturas que se edificam com base em processos de trabalho individuais e coletivos, potenciadores da reconstrução de novas visões sobre a ação docente e o sobre a mudança educacional e organizacional.

Neste sentido, os processos de mudança, e neste caso específico da mudança como processo que visa melhorar a escola (Glatter, 1992), exigem formas de identificação e ressignificação por cada um dos professores como sujeito individual na representação do coletivo de que faz parte (Velloso; Granja, 2016). Defende-se, nesta perspetiva, que as mudanças tendem a ser fruto dos próprios profissionais (professores) numa dimensão individual, desejando-se, em consequência, que se constituam como coletivas por meio de processos de trabalho colaborativo entre pares.

Considerando que a mudança em educação é quase sempre justificada no quadro de diretrizes políticas, tem sido sustentado uma visão de politica que potencialize, e não negligencie, a dimensão de subjetividades individuais transposta para uma assunção de um coletivo comprometido e responsável no contexto de ação - a escola. Isto é, políticas que, entendidas como um ciclo continuo entre o nível discursivo e o nível da prática (Ball, 2002; Mainardes, 2006), permitem, nomeadamente “[...] no nível micro, a sala de aula; o nível meso, a escola e (a) comunidade” (Oliveira; Courela, 2013, p. 103) ser reinterpretadas pelos professores, e outros agentes educativos, em prol da reconfiguração das práticas curriculares e da mudança da organização escolar. É no quadro destas ideias que, em linha com 
argumentos anteriormente explicitados, tem cabimento um entendimento do papel dos professores como principais agentes, individual e coletivamente, de mudança e se reconhece também a importância de, do ponto de vista dos discursos políticos, lhes ser dada visibilidade (Leite; Fernandes, 2010; Nóvoa, 2009). Com efeito, pese embora, em Portugal, os discursos das políticas curriculares tendam, sobretudo desde as últimas décadas do século XX, a conferir centralidade aos professores nos processos de gestão, contextualização e diferenciação curricular (Roldão, 2003; Fernandes et al., 2013; Trindade; Cosme, 2014), temse vindo a assistir a um deslocamento dessa centralidade para o contexto escola. Se, por um lado, esse deslocamento pode simbolizar o reforço de uma politica que preconiza um sentido de mudança assente no coletivo dos profissionais da escola, por outro, pode também representar um certo silenciamento do protagonismo individual do professor, contribuindo para maior invisibilidade social do seu papel. Parece ser à luz deste mesmo argumento que Nóvoa (2011) tem vindo a reclamar o regresso dos professores à cena educativa, salientando que, nas últimas quatro décadas, as políticas educativas geraram como subproduto a invisibilidade social dos professores, com o deslocamento para outros enfoques e contextos.

Este cenário de “politicas hibridas” (Lopes, 2005) tem exigido aos professores tornaremse “profissionais híbridos” (Faulconbridge; Muzio, 2008; Noordegraaf, 2015), isto é, assumirem-se como "profissionais compósitos”, congregando elementos que geralmente são identificados separadamente em profissionais (Fischer; Ferlie, 2013). Esta reconfiguração do papel dos professores é associada ao neoliberalismo e 'fundamentalismo de mercado' nos últimos 30 anos (Leicht, 2016), e à sua influência em políticas públicas que adotam mecanismos de supervisão e controle (Evetts, 2013; Noordegraaf, 2007, 2015) do trabalho docente.

Esses mecanismos de regulações e controle, podem instituir-se quer a nível nacional, quer local (Reis, 2013), e são caracterizados também pelo "efeito de hibridismo que resulta da sobreposição ou mestiçagem de diferentes lógicas, discursos e práticas na definição e ação públicas, o que reforça o seu carácter ambíguo e compósito” (Barroso, 2003, p. 24). É na base deste hibridismo que, sobretudo desde as ultimas décadas do século XX, se tem situado a gestão das políticas educacionais e curriculares, e se têm reconfigurado os perfis profissionais e organizacionais. Esta situação tem sido objeto de critica, alertando-se sobretudo para os riscos daquele hibridismo quer ao nível do ofício docente, quer da missão da escola (Corazza, 2001). Argumenta-se que esse caráter híbrido, assente em mecanismos de regulação centralizada e localizada, pode condicionar o exercício profissional, e a cultura organizacional, subjugando-os a lógicas de mercantilização no âmbito das quais os professores são “colonizados e subalternizados (por) experts que centralmente decidem o agir profissional [...] sem que estes tenham voz sobre as questões de vida pública que dizem respeito à sua profissão” (Bonifácio; Azevedo, 2017, p. 127).

Em concordância com estas advertências, reconhece-se que as politicas híbridas podem potencializar formas disfarçadas de regulação e controle do trabalho docente e escamotear processos de subalternização do professor na sua autonomia individual 


\section{Metodologia}

A pesquisa é de natureza qualitativa (Amado, 2014), com recurso à análise documental (Bogdan; Biklen, 1994; Raupp; Beuren, 2006) e análise de conteúdo (Bardin, 2011) com recurso ao software NVivo foi feita uma análise articulada aos documentos: i) Perfil do aluno à saída da escolaridade obrigatória (Portugal, 2017); ii) Educação inclusiva (Portugal, 2018a); e iii) Autonomia e flexibilidade curricular (Portugal, 2018b) em duas fases - na primeira identificou-se a representatividade dos termos: escola/as e professor/es; a segunda, assentou numa leitura flutuante dos três documentos e identificação de categorias de análise e respetivas unidades de registo e na interpretação dos discursos e construção de inferências. Foram identificadas duas categorias de análise: i) conceção/papel de professor; ii) lógicas de regulação docente para que apontam as politicas curriculares em análise, A apresentação e discussão dos dados segue este sistema categorial.

\section{Apresentação e discussão dos dados}

Considerando as categorias de análise, os dados são apresentados focando, primeiro, a conceção de professor expressa nos textos em análise e situando, depois, lógicas de regulação docente para que apontam as políticas curriculares em análise.

Uma primeira leitura focalizada na representatividade terminológica escola/escolas e professor/professores mostra, nos três documentos em análise, uma maior centralidade na palavra escola(s) por relação com a palavra professor(es): no PASEO existem 14 referências à escola(s) e 2 referência a professor(es); no Decreto-Lei n. ${ }^{0}$ 55/2018 (Portugal, 2018b) identificam-se 63 referências à palavra escola(s) e 14 à palavra professor(es); no Decreto-Lei n. ${ }^{\circ}$ 54/2018 (Portugal, 2018a) existem 77 referências à escola(s) e 3 referências a professor(es). Esta leitura aponta para uma certa sintonia discursiva entre as três propostas curriculares lançadas no final da segunda década do século XXI em Portugal, aspeto que é corroborado por Fernandes e Oliveira (2019) na análise que fazem desses discursos oficiais sobre educação inclusiva e flexibilidade curricular.

De forma semelhante, também a análise referenciada às categorias evidencia essa articulação e sintonia discursivas. Iniciando pelo PASEO (Portugal, 2017), as referências a uma conceção de professor são muito pouco explicitas, observando-se a mesma tendência de ênfase na escola, tal como ilustra o seguinte excerto:

É neste contexto que a escola, enquanto ambiente propício à aprendizagem e ao desenvolvimento de competências, onde os alunos adquirem as múltiplas literacias que precisam de mobilizar, tem que se ir reconfigurando para responder às exigências destes tempos de imprevisibilidade e de mudanças aceleradas. (Portugal, 2017, p. 9) 
A referência aos professores surge a par de outros atores educativos, revelando, assim, pouca centralidade no discurso desta politica curricular:

O Perfil dos Alunos configura o que se pretende que os jovens alcancem no final da escolaridade obrigatória, sendo, para tal, determinante o compromisso da escola e de todos os que lá trabalham, a ação dos professores e o empenho das famílias e encarregados de educação. (Portugal, 2017, p. 9)

Os princípios enunciados no PASEO, nomeadamente os princípios de Inclusão e Coerência e flexibilidade (p. 13), expressam a escola como núcleo discursivo:

A escola contemporânea agrega uma diversidade de alunos tanto do ponto de vista socioeconómico e cultural como do ponto de vista cognitivo e motivacional. Todos os alunos têm direito ao acesso e à participação de modo pleno e efetivo em todos os contextos educativos. (Princípio de inclusão, Portugal, 2017, p. 13).

Garantir o acesso à aprendizagem e à participação dos alunos no seu processo de formação requer uma ação educativa coerente e flexível. É através da gestão flexível do currículo e do trabalho conjunto dos professores e educadores sobre o currículo que é possível explorar temas diferenciados, trazendo a realidade para o centro das aprendizagens visadas. (Portugal, 2017, p. 13)

Pese embora a centralidade dos discursos na escola, pode desocultar-se nestes discursos, de forma não explícita, uma conceção de professor como configurador, e diferenciador, do currículo (Leite; Fernandes, 2010; Roldão, 2003), atento à diversidade dos alunos e promotor de uma educação inclusiva (Leite; Fernandes, 2007; Rodrigues, 2014).

Parece também poder compreender-se que a gestão flexível do currículo constitui um caminho que permite explorar e fomentar situações de ensino aprendizagem contextualizadas aos interesses e especificidades dos alunos convocando-os à participação na sua formação.

Estabelecendo uma articulação com o Decreto Lei n. ${ }^{\circ}$ 54/2018 (Portugal, 2018a), o discurso é, igualmente, centrado na escola. Este diploma legal enuncia a importância de uma escola inclusiva, atenta à diversidade dos alunos:

Aposta numa escola inclusiva onde todos e cada um dos alunos, independentemente da sua situação pessoal e social, encontram respostas que lhes possibilitam a aquisição de um nível de educação e formação facilitadoras da sua plena inclusão social. (Portugal, 2018a, Preâmbulo)

O presente decreto-lei tem como eixo central de orientação a necessidade de cada escola reconhecer a mais-valia da diversidade dos seus alunos, encontrando formas de lidar com essa diferença, adequando os processos de ensino às características e condições individuais de cada aluno, mobilizando os meios de que dispõe para que todos aprendam e participem na vida da comunidade educativa. (Portugal, 2018a) 
Na linha do raciocínio até agora feito, e mesmo não sendo feita menção à palavra professor (recorde-se que apenas foram identificadas 3 referências ao termo "professor/es") pode, também, depreender-se deste discurso uma visão de professor como agente decisor do currículo (Priestley; Biesta; Robinson, 2013, 2015; Morgado, 2016) , expressa nas ideias qua apontam para a capacidade de encontrar formas de lidar com a diferença, adequar os processos de ensino às características dos alunos, proporcionando condições para que todos aprendam de modo mais significativo.

Também o Decreto-Lei n. ${ }^{\circ}$ 55/2018 (Portugal, 2018b), sobre o Projeto de Autonomia e Flexibilidade Curricular, coloca a ênfase na escola, ainda que, "timidamente”, se referenciem também os professores:

Considera-se fundamental que as principais decisões a nível curricular e pedagógico sejam tomadas pelas escolas e pelos professores. É neste enquadramento que no presente decreto-lei se desafiam as escolas, conferindolhes autonomia para, em diálogo com os alunos, as famílias e com a comunidade poderem (entre outros aspetos):

Dispor de maior flexibilidade na gestão curricular, com vista à dinamização de trabalho interdisciplinar, de modo a aprofundar, reforçar e enriquecer as Aprendizagens Essenciais;

Adotar diferentes formas de organização do trabalho escolar, designadamente através da constituição de equipas educativas que permitam rentabilizar o trabalho docente e centrá-lo nos alunos;

Apostar na dinamização do trabalho de projeto (...) valorizando o papel dos alunos enquanto autores, proporcionando-lhes situações de aprendizagens significativas. (Portugal, 2018b)

Estes, e outros, aspetos evidenciam uma clara centralidade do discurso na escola, permitindo inferir que a concessão de maior autonomia às escolas será condição para a dinamização do trabalho interdisciplinar, a adoção de equipas educativas com base na concretização de lógicas de trabalho colaborativo (quer no plano disciplinar, quer no plano interdisciplinar) como forma de organização do trabalho escolar e a dinamização de projetos que propiciem a participação dos alunos na compreensão da complexidade do real como forma de lhes proporcionar a realização de aprendizagens significativas (Roldão; Almeida, 2018).

Similarmente, este decreto lei sublinha a importância de uma escola inclusiva que responda às necessidades de todos os alunos,

Uma escola inclusiva, promotora de melhores aprendizagens para todos os alunos e a operacionalização do perfil de competências que se pretende que os mesmos desenvolvam, para o exercício de uma cidadania ativa e informada ao longo da vida, implicam que seja dada às escolas autonomia para um desenvolvimento curricular adequado a contextos específicos e às necessidades dos seus alunos. (Portugal, 2018b, Preâmbulo) 
Observa-se, também aqui, uma ausência de referência ao papel do professor. Embora possamos considerar que esta pouca centralidade no professor possa ter tido a intenção de fazer deslocar o ônus da responsabilidade da decisão curricular do individual (professor) para o coletivo (escola), não podemos deixar de reconhecer que este discurso de natureza mais abstrata pode ter o efeito perverso de se fazer pensar a escola como um lugar "sem rostos", conduzindo a uma maior desresponsabilização individual e coletiva. Reconhecendo, em linha com vários autores (Hargreaves, 1998; Nóvoa, 2009; Leite; Fernandes, 2010; Priestley; Biesta; Robinson, 2013, 2015; Van Der Heijden et al., 2015) que os professores são os principais agentes da mudança consideramos importante que do ponto de vista dos discursos das políticas curriculares lhes seja dada visibilidade. Como fomos notando, pese embora não seja um discurso explícito, advinha-se que subjacente a estas orientações está a esperança de os professores se assumirem como profissionais ativos, capazes de realizarem processos de contextualização e diferenciação curricular (Fernandes et al., 2013; Trindade; Cosme, 2014) que promovam a realização de aprendizagens significativas para todos os alunos.

Relativamente à categoria lógica de regulação docente para que apontam as políticas curriculares, é expresso no PASEO (Portugal, 2017) o seguinte:

O Perfil dos Alunos à Saída da Escolaridade Obrigatória [...], afirma-se como referencial para as decisões a adotar por decisores e atores educativos ao nível dos estabelecimentos de educação e ensino e dos organismos responsáveis pelas políticas educativas, constituindo-se como matriz comum para todas as escolas e ofertas educativas no âmbito da escolaridade obrigatória, designadamente ao nível curricular, no planeamento, na realização e na avaliação interna e externa do ensino e da aprendizagem. (Portugal, 2017, Nota introdutória)

As ideias de "referencial para as decisões a adotar por decisores e atores educativos" e de "matriz comum para todas as escolas e professores" apontam para uma tendência de uniformização das decisões curriculares. Na mesma direção parece poder ser situada a referência feita na introdução:

O Perfil dos Alunos à Saída da Escolaridade Obrigatória afirma-se, [...] como documento de referência para a organização de todo o sistema educativo, contribuindo para a convergência e a articulação das decisões inerentes às várias dimensões do desenvolvimento curricular. (Portugal, 2017, p. 8)

Analisando estes dois excertos em articulação com a ideia de que "A referência a um perfil não visa, porém, qualquer tentativa uniformizadora” (Portugal, 2017, p. 5) observa-se uma certa ambiguidade, indicativa de um certo hibridismo (Lopes, 2005) e, até, de alguma contradição discursiva. Mais do que dissimular aquela tendência de uniformização, esta salvaguarda parece acentuá-la e deixar implícita uma lógica centralizada de regulação docente (Reis, 2013). 
Atentando mais cuidadosamente na análise do documento observa-se nova ressalva discursiva relativamente ao PASEO, que parece contraditar a inferência antes construída:

O Perfil dos Alunos configura o que se pretende que os jovens alcancem no final da escolaridade obrigatória, sendo, para tal, determinante o compromisso da escola e de todos os que lá trabalham, a ação dos professores e o empenho das famílias e encarregados de educação. (Portugal, 2017, p. 9)

Com efeito, as ideias de “compromisso da escola e de todos os que lá trabalham” e de “ação dos professores e o empenho das famílias e encarregados de educação” remetem para uma responsabilização participada e partilhada das decisões curriculares que parece também deixar implícita uma lógica localizada de regulação docente (Reis, 2013). Esta interpretação é corroborada pelos descritores operativos, expressos no final de cada área de competência. Veja-se, a titulo de exemplo, o descritor operativo da área de Relacionamento Interpessoal,

Os alunos envolvem-se em conversas, trabalhos e experiências formais e informais: debatem, negoceiam, acordam, colaboram. Aprendem a considerar diversas perspetivas e a construir consensos. Relacionam-se em grupos lúdicos, desportivos, musicais, artísticos, literários, políticos e outros, em espaços de discussão e partilha, presenciais ou a distância. (Portugal, 2017, p. 25)

Como parece evidente, este descritor, ao mesmo tempo que remete para uma indicação implícita de estratégias de ação docente, aponta também para a ideia de verificação, por parte dos professores, do cumprimento do descritor, indiciando, assim, um procedimento prescritivo de (auto)regulação docente.

Analisando, por este prisma, o Decreto-Lei n. ${ }^{0}$ 54/2018 (Portugal, 2018a), nele pode observar-se uma certa harmonia discursiva, nomeadamente quanto à ideia implícita de uma lógica centralizada de regulação docente:

Consciente das competências profissionais existentes nas escolas portuguesas, o Governo pretende agora criar condições para que estas possam elevar os padrões de qualidade das diferentes ofertas de educação e formação. (Portugal, 2018a, Preâmbulo)

Ainda que fazendo referencia às escolas, o Governo surge no discurso como a entidade reguladora dos padrões de qualidade a alcançar nas escolas. Simultaneamente, e à semelhança, do PASEO, são veiculadas indicações que remetem para uma lógica de regulação localizada da ação docente:

As opções metodológicas subjacentes ao presente decreto-lei assentam no desenho universal para a aprendizagem e na abordagem multinível no acesso ao currículo. Esta abordagem baseia-se [...] no acompanhamento e monitorização sistemática da eficácia do contínuo das intervenções implementadas, no diálogo dos docentes com os pais ou encarregados de educação e na opção por medidas 
de apoio à aprendizagem, [...] de acordo com as respostas educativas necessárias para cada aluno adquirir uma base comum de competências, valorizando as suas potencialidades e interesses. (Portugal, 2018a, Preâmbulo)

Pode, pois, observar-se neste excerto uma certa dualidade discursiva que remete quer para uma lógica de regulação docente centralizada, expressa nas ideias de "desenho universal para a aprendizagem” e "na abordagem multinível no acesso ao currículo”, quer para uma lógica de regulação docente localizada, expressa nas ideias de "acompanhamento e monitorização sistemáticas da eficácia do contínuo das intervenções implementadas” e no “diálogo dos docentes com os pais ou encarregados de educação", conferindo um caráter híbrido (Barroso, 2003; Lopes, 2004) a estas politicas curriculares. Este caráter híbrido é patente no enunciado do Artigo 33. ${ }^{\circ}$ (Portugal, 2018a), no qual se determina por um lado que

O acompanhamento da aplicação do presente decreto-lei é assegurado a nível nacional por uma equipa, que integra elementos dos serviços com atribuições nesta matéria, a designar pelos respetivos membros do Governo, podendo ainda integrar representantes dos Governos das Regiões Autónomas dos Açores e da Madeira. (Portugal, 2018a, ponto 1)

E, por outro, que

As escolas devem incluir nos seus relatórios de autoavaliação as conclusões da monitorização da implementação das medidas curriculares, dos recursos e estruturas de suporte à educação inclusiva. (Portugal, 2018a, ponto 2)

A lógica de regulação localizada é também expressa no artigo $12 .^{\circ}$, relativo à Equipa multidisciplinar de apoio à educação inclusiva, no qual se determinam as atribuições que cabem ao diretor do Agrupamento e aos coordenadores da equipa multidisciplinar. Entre outros aspetos, cabe ao diretor, designar: os elementos permanentes (da equipa multidisciplinar); coordenador da equipa e o local de funcionamento (ponto 5). Cabe ao coordenador da equipa multidisciplinar, entre outras responsabilidades, convocar os membros da equipa para as reuniões; dirigir os trabalhos e adotar os procedimentos necessários de modo a garantir a participação dos pais ou encarregados de educação (ponto $6)$.

Analisando o Decreto-Lei n. o 55/2018 (Portugal, 2018b), constata-se uma clara articulação com o PASEO, nomeadamente quanto à ideia de uniformização das decisões curriculares:

Impulsionados por tais desafios e correspondendo a esta necessidade, após amplo debate nacional que envolveu professores, académicos, famílias, parceiros sociais e alunos, foi aprovado o Perfil dos Alunos à Saída da Escolaridade Obrigatória, que estabelece a matriz de princípios, valores e áreas de competências a que deve obedecer o desenvolvimento do currículo. (Portugal, 2018b, Preâmbulo) 
Igualmente, este enunciado parece reportar para uma lógica de regulação docente centralizada representada na ideia de que o PASEO "estabelece a matriz de princípios, valores e áreas de competências a que deve obedecer o desenvolvimento do currículo", transmitindo, de forma implícita, uma prescrição de estratégias de ação docente a serem seguidas. A ideia de ambiguidade discursiva atravessa também as determinações expressas neste documento curricular designadamente quando é expresso que:

A assunção do papel decisivo das escolas e dos professores no processo educativo dos alunos leva o Ministério da Educação a assumir um papel subsidiário do trabalho das escolas, prevendo-se, por isso, no presente decreto-lei, a instituição de um mecanismo de apoio e acompanhamento do trabalho das escolas no sentido de o reforçar e impulsionar criando entre as escolas e comunidades e redes de partilha de práticas. (Portugal, 2018b, Preâmbulo)

Com efeito, este mesmo excerto induz para uma lógica centralizada de regulação docente, manifestada na ideia "leva o Ministério da Educação a assumir um papel subsidiário do trabalho das escolas (instituindo) um mecanismo de apoio e acompanhamento do trabalho das escolas” e, simultaneamente, para uma lógica localizada de (auto)regulação docente, revelada nas ideias de reforço e impulsionamento de redes de partilha de práticas entre as escolas, e de que no processo de planeamento curricular:

Deve ser garantida a prática regular de monitorização do planeamento curricular, avaliando o impacto das opções adotadas nos termos do número anterior, com vista à promoção dos ajustamentos necessários. (Portugal, 2018b, Artigo 18. )

A associação destas ideias com a que remete para a determinação de que o planeamento curricular deve ter "como finalidade a adequação e contextualização do currículo ao projeto educativo da escola e às características dos alunos” (artigo 18. ${ }^{\circ}$ ), permite ainda a interpretação de uma visão política, ainda que não explicitamente enunciada, que parece conferir centralidade ao professor. Uma centralidade que está presente nas ideias de contextualização do currículo e na sua adequação às características dos alunos, num entendimento do papel do professor como decisor e configurador do currículo (Fernandes et al., 2013; Cosme, 2018; Leite; Fernandes, 2010; Trindade; Cosme, 2014).

Em síntese, a análise permitiu observar que os discursos dos documentos da política curricular analisados, ainda que coloquem a centralidade no contexto escola, deixam transparecer registos que apontam para a importância do papel do professor nos processos de gestão e de desenvolvimento do currículo. Esta caraterística, como argumentámos, ao mesmo tempo que remete para um caráter hibrido das politicas (Lopes, 2005) convoca, igualmente, para uma conceção de professor como "profissionais híbridos" (Faulconbridge; Muzio, 2008; Noordegraaf, 2015). Esta visão encerra em si, também como sustentámos, lógicas de regulação do trabalho docente centralizadas/localizadas (Evetts, 2013; Noordegraaf, 2007, 2015; Reis, 2013) que parecem denunciar novos desafios para os professores nos seus quotidianos profissionais. 


\section{Considerações finais}

O estudo a que se reporta este artigo analisa a centralidade do professor expressa nas propostas políticas de autonomia e flexibilidade curricular e de uma Educação Inclusiva, em curso desde 2017/2018 em Portugal, na sua relação com possíveis lógicas de regulação.

Nesse âmbito, os dados foram organizados segundo duas principais categorias de análise: i) conceção/papel de professor; ii) lógicas de regulação docente para que apontam as políticas curriculares em análise. Situando-nos na primeira categoria, a análise dos três documentos evidencia, uma vigorosa representatividade terminológica das palavras escola/escolas e uma reduzida alusão aos termos professor/professores. Esta leitura é também visível no que concerne a ideias configuradoras de uma conceção de professor. Ou seja, observa-se um esvaziamento discursivo quanto a uma conceção de professor, como agente educativo, e um deslocamento para uma conceção de um agente coletivo configurado na ideia de escola. Reconhecendo que esta situação pode ter a mais valia de contribuir para fortalecer lógicas de atuação coletiva, e socialmente comprometidas, consideramos também que essa ênfase discursiva pode concorrer para leituras de uma escola como um lugar "sem rostos”. Isto é, uma escola que, em nome de um “nós”, de um coletivo, pode escamotear lógicas de silenciamento das subjetividades da ação do professor e do seu protagonismo individual, alimentando a sua invisibilidade social (Nóvoa, 2011).

Pese embora estas considerações, a análise permitiu ainda inferir, nas entrelinhas dos discursos dos três documentos, uma conceção do papel de professor como agente (re)configurador, e diferenciador do currículo (Leite; Fernandes, 2010; Marinho; Delgado, 2019; Roldão, 2003), adivinhando-se uma intenção política que parece depositar no poder de “agência dos professores” (Priestley; Biesta; Robinson, 2013, 2015) a possibilidade de concretização de princípios de uma educação inclusiva.

No que se refere à segunda categoria, lógicas de regulação docente, os documentos analisados apontam para uma ambiguidade e dualidade discursivas. Isto é, os discursos tendem a remeter para lógicas de regulação da ação docente emanadas do poder central e, simultaneamente, para ordens localmente outorgadas, conferindo um caráter híbrido a estas políticas curriculares (Lopes, 2004). Este hibridismo, enraizado em fundamentos e ordens neoliberais, traz desafios aos professores e aos seus contextos de ação, requerendo a sua reconfiguração em "profissionais híbridos" (Faulconbridge; Muzio, 2008; Noordegraaf, 2015) sujeitos a mecanismos de regulação e controle igualmente ambíguos e compósitos (Barroso, 2003).

Neste sentido, argumenta-se que este "profissional composito/híbrido” que se tem vindo a afirmar nas políticas educacionais e curriculares, pode camuflar não apenas visões fictícias quanto ao papel do professor, simbolizadas, por exemplo, no apelo incessante ao trabalho colaborativo, como se este fosse a receita eficaz para os "males" da educação escolar, como também potencializar processos de regulação e controle do trabalho docente, e uma subalternização da sua autonomia. Esta situação pode conduzir o professor a um sentimento 
de não autoria do seu próprio fazer profissional, e a um entendimento de que suas experiências e saberes não são reconhecidos pelos decisores políticos centrais responsáveis pela formulação de políticas que regulam e dirigem a sua ação (Selles; Andrade, 2016).

Em síntese, a análise realizada neste estudo leva-nos a considerar que, no quadro das diretrizes políticas curriculares analisadas, tem vindo a assistir-se a um deslocamento da centralidade da pessoa do professor para o contexto global da escola. Se, por um lado essas diretrizes podem apontar para uma visão de agente educativo como um agente coletivo, por outro, como se referiu, podem correr o risco de silenciar e invisibilizar a ação individual de cada professor.

Orientando-nos pelo pressuposto de que a escola é um lugar de "rostos" sustentamos a ideia de que o professor, a par de outros agentes, deve ter visibilidade nos discursos da politica curricular pela centralidade que lhe reconhecemos na reconfiguração dessas politicas (Ball, 2002), contextualizando-as às realidades socio-educacionais em que atua.

\section{Referências}

AFONSO, A. J. Para uma concetualização alternativa de accountability em educação. Educação \& Sociedade, Campinas, v. 33, n. 119, p. 471-484, jun. 2012. DOI 10.1590/S0101-73302012000200008. Disponível em: https://doi.org/10.1590/S0101-73302012000200008

AMADO, J. Manual de investigação qualitativa em educação. Coimbra: Imprensa da Universidade de Coimbra, 2014.

BALL, S. J. Diretrizes e políticas globais e relações políticas locais em educação. Currículo Sem Fronteiras, Porto Alegre, v. 1, n. 2, p. 99-116, 2001.

BALL, S. J. Educação global S. A.: novas redes de políticas e o imaginário neoliberal. Tradução: Janete B. Ponta Grossa: UEPG, 2014. 270p.

BALL, S. J. The teacher's soul and the terrors of performativity. Journal of Education Policy, v. 18, n. 2, p. 215-228, 2003. DOI 10.1080/0268093022000043065. Disponível em: https://doi.org/10.1080/0268093022000043065

BALL, S. Reformar escolas/reformar professores e os terrores da performatividade. Revista Portuguesa de Educação, Braga, v. 15, n. 2, p. 03-23. 2002.

BARDIN, L. Análise de conteúdo. Lisboa: Edições 70, 2011.

BARROSO, J. Os novos modos de regulação das políticas educativas na Europa: da regulação do sistema a um sistema de regulações. Educação em Revista, Belo Horizonte, n. 39, p. 19-28, jul. 2004. Disponível em: http://educa.fcc.org.br/scielo.php?script=sci_arttext\&pid=S010246982004000100003\&lng=pt\&nrm=iso\&tlng=pt

BARROSO, J. Regulação e desregulação nas políticas educativas: tendências emergentes em estudos de educação comparada. In: BARROSO, J. A escola pública: regulação, desregulação privatização. Porto: Edições Asa, 2003. p. 19-48.

BOGDAN, R.; BIKLEN, S. Investigação qualitativa em educação: fundamentos, métodos e técnicas. Porto: Porto Editora, 1994.

BOLÍVAR, A. El mejoramiento de la escuela: líneas actuales de investigación, Revista Portuguesa de Pedagogia, [s. 1.], v. 51, n. 2, p. 5-27, 2017. DOI: https://doi.org/10.14195/1647-8614_51-2_1.

BOLÍVAR, A. Melhorar os processos e os resultados educativos: o que nos ensina a investigação. Porto: 
Fundação Manuel Leão, 2012.

BONIFÁCIO, E.; AZEVEDO, M. L. Diz-nos quem te ensina e dir-te-emos quem é um bom professor. In: Manuel V. P. et al. (ed.). II Encontro Internacional de Formação na Docência (INCTE): livro de atas. Bragança: Instituto Politécnico de Bragança, 2017. p. 121-128.

COELHO, A. M. Regulação política e reconfiguração do perfil profissional do diretor de escola: a opinião dos membros do conselho das escolas. 2014. 268 p. Tese. (Doutoramento em Educação) - Instituto de Educação, Universidade de Lisboa, Lisboa, 2014.

CORAZZA, S. Currículos alternativos/oficiais: o(s) risco(s) do hibridismo. Revista Brasileira de Educação, Rio de Janeiro, n. 17, p. 100-114, ago. 2001. Disponível em: https://doi.org/10.1590/S141324782001000200008

COSME, A. Autonomia e flexibilidade curricular: propostas e estratégias de ação, ensino básico, ensino secundário. Porto: Porto Editora, 2018.

DALE, R. A globalização e o desenho do terreno curricular / Globalisation and the shaping of the terrain of the curriculum. Revista Espaço do Currículo, v. 1, n. 1, p. 12-33, 2008. DOI 10.22478/ufpb.1983-1579. Disponível em: https://doi.org/10.15687/rec.v1i1.3640

EVETTS, J. Professionalism: value and ideology. Current Sociology, v. 61, n. 5-6, p. 778-796, 2013. DOI 10.1177/0011392113479316. Disponível em: http://dx.doi.org/10.1177/0011392113479316

FAULCONBRIDGE, J.; MUZIO, D. Organizational professionalism in globalizing law firms. Work, Employment and Society, v. 22, n. 1, p. 7-25, mar. 2008. DOI 10.1177/0950017007087413. Disponível em: https://doi.org/10.1177/0950017007087413

FERNANDES, P.; LEITE, C.; MOURAZ, A.; FIGUEIREDO, C. Curricular contextualization: tracking the meanings of a concept. The Asia-Pacific Education Researcher, v. 22, p. 417-425, 2013. Disponível em: https://doi.org/10.1007/s40299-012-0041-1

FERNANDES, P.; OLIVEIRA, E. Educação inclusiva e flexibilidade curricular: aproximações e distanciamentos entre discursos "oficiais” e discursos de professores. Revista de Estudos Curriculares, v. 10, n. $2, \quad$ p. $\quad 52-73, \quad 2019 . \quad 20$ Disponível em: https://www.nonio.uminho.pt/rec/index.php?journal=rec\&page=article\&op=view\&path\%5B\%5D=85

FERNNADES, P. O currículo do ensino básico em Portugal: políticas, perspectivas e desafios. Porto: Porto Editora, 2011.

FIGUEIREDO, Carla; LEITE, Carlinda; FERNANDES, Preciosa. Entre os enunciados políticos e os corredores de liberdade nas práticas curriculares dos professores. Educ. Pesqui., v. 45, e189917, 2019. Doi 10.1590/S1678-4634201945189917

FISCHER, M. D.; FERLIE E. Resisting hybridisation between modes of clinical risk management: contradiction, contest, and the production of intractable conflict. Accounting, Organizations and Society, v. 38, n. 1, p. 30-49, Jan. 2013. DOI 10.1016/j.aos.2012.11.002. Disponível em: https://doi.org/10.1016/j.aos.2012.11.002

FULLER, K. "That would be my red line": an analysis of headteachers resistance of neoliberal education reforms. Educational Review, Londres, v. 71 , n. 1, p. 31-50, set. 2018. DOI 10.1080/00131911.2019.1522042. Disponível em: https://doi.org/10.1080/00131911.2019.1522042

GLATTER, R. A gestão como meio de inovação e mudança nas escolas. In António Nóvoa, As organizações escolares em análise. Lisboa: Publicações Dom Quixote, 1992.

HARGREAVES, A. Os professores em tempos de mudança: o trabalho e a cultura dos professores na idade pós-moderna. Lisboa: Mc Graw-Hill, 1998.

LEICHT, K. T. Market fundamentalism, cultural fragmentation, post-modern skepticism, and the future of professional work. Journal of Professions and Organization, Oxford, v. 3, n. 1, p. 103-117, ago. 2016. DOI 10.1093/jpo/jov006. Disponível em: https://doi.org/10.1093/jpo/jov006 
LEITE, C. A territorialização das políticas e das práticas educativas. In: LEITE, C. (org). Mudanças curriculares em Portugal: transição para o século XXI. Porto: Porto Editora, 2005. p. 15-32.

LEITE, C.; FERNANDES, P. Curricular studies and their relation with the political agenda for education. Transnational Curriculum Inquiry, Rio de Janeiro, v. 9, n. 2, p. 35-49, jan. 2012. DOI 10.14288/tci.v9i2.183780. Disponível em: https://doi.org/10.14288/tci.v9i2.183780

LEITE, C.; FERNANDES, P. Desafios aos professores na construção de mudanças educacionais e curriculares: que possibilidades e que constrangimentos?. Educação, v. 33, n. 3, dez. 2010. Disponível em: https://revistaseletronicas.pucrs.br/ojs/index.php/faced/article/view/8076

LEITE, C.; FERNANDES, P. Desafios para um currículo escolar comprometido com a inclusão. Educação: Temas e Problemas, Lisboa, v. 3, p. 203-215, 2007.

LIMA, Licínio. C. A gestão democrática das escolas: do autogoverno à ascensão de uma pós-democracia gestionária? Educação e Sociedade, v. 35, n. 129, 1067-1083, 2014. https://doi.org/10.1590/ES010173302014142170

LOPES, A. C. Política de currículo: recontextualização e hibridismo. Currículo Sem Fronteiras, Porto Alegre, v. $5, \quad$ n. 2, $\quad$ p. 50-64, jul./dez. 2005. Disponível em: http://www.curriculosemfronteiras.org/vol5iss2articles/lopes.htm

LOPES, A. C. Políticas curriculares: continuidade ou mudança de rumos? Revista Brasileira de Educação, Rio de Janeiro, n. 26, p. 109-118, ago. 2004. DOI 10.1590/S1413-24782004000200009. Disponível em https://doi.org/10.1590/S1413-24782004000200009

MAINARDES, J. Abordagem do ciclo de políticas: uma contribuição para a análise de políticas educacionais. Educação e Sociedade, v. 27, n. 94, p. 47-69, 2006. DOI 10.1590/S0101-73302006000100003. Disponível em: https://doi.org/10.1590/S0101-73302006000100003

MARINHO, P.; LEITE, C.; FERNANDES, P. “Germ Infecioso” nas culturas escolares: Possibilidades e limites da política de autonomia e flexibilização curricular em Portugal. Currículo sem Fronteiras, Porto Alegre, v. 19, n. 3, p. 923-943, set./dez. 2019. Disponível em: http://www.curriculosemfronteiras.org/vol19iss3articles/marinho-leite-fernandes.html

MARINHO; P.; DELGADO, F. A curriculum in vocational courses: the recognition and (re)construction of counterhegemonic knowledge. The Educational Forum, v. 83, n. 3, p. 251-265, 2019. DOI 10.1080/00131725.2019.1599650. Disponível em: https://doi.org/10.1080/00131725.2019.1599650

MORGADO, J. C. O professor como decisor curricular: de ortodoxo a cosmopolita. Revista Tempos e Espaços em Educação, Sergipe, v. 9, n. 18, p. 55-64, jan./abr. 2016. DOI 10.20952/revtee.v9i18.4964. Disponível em: https://doi.org/10.20952/revtee.v9i18.4964

NOORDEGRAAF, M. From 'pure' to 'hybrid' professionalism: present-day professionalism in ambiguous public domains. Administration \& Society, v. 39, n. 6, p. 761-785, 2007. DOI 10.1177/0095399707304434. Disponível em: https://doi.org/10.1177/0095399707304434

NOORDEGRAAF, M. Hybrid professionalism and beyond: (new) forms of public professionalism in changing organizational and societal contexts. Journal of Professions and Organization, v. 2, n. 2, p. 187-206, Sep. 2015. DOI 10.1093/jpo/jov002. Disponível em: https://doi.org/10.1093/jpo/jov002

NORTHOUSE, P. Leadership: theory and practice. 7. ed. Thousand Oaks: Sage Publications, 2016. 494 p.

NÓVOA, A. et al. Pesquisa em educação como processo dinâmico, aberto e imaginativo: uma entrevista com António Nóvoa. Educação \& Realidade, v. 36, n. 2, p. 533-543, 2011. Disponível em: https://seer.ufrgs.br/educacaoerealidade/article/view/21170

NÓVOA, A. Professores: imagens do futuro presente. Lisboa: Educa, 2009. 96 p.

OLIVEIRA, I.; COURELA, C. Mudança e inovação em educação: o compromisso dos professores. Interacções, v. 9, n. 27, p. 97-117, 2013. DOI 10.25755/int.3404. Disponível em: https://doi.org/10.25755/int.3404 
ONU. Guia sobre Desenvolvimento Sustentável: 17 OBJETIVOS PARA TRANSFORMAR O NOSSO MUNDO. Centro de Informação Regional das Nações Unidas para a Europa Ocidental, 2018. Disponível em: www.unric.org/pt

PACHECO, José, A.; SOUSA, J. Políticas curriculares no período pós-LBSE (1986-2017): ciclo de mudanças na educação pré-escolar e nos ensinos básicos e secundários. In J. A. Pacheco, M. C. Roldão \& M. T. Estrela, Estudos de currículo, p. 129-176. Porto: Porto, 2018.

PORTUGAL. Decreto-Lei n. ${ }^{\circ}$ 54/2018, de 6 de julho de 2018. Estabelece o regime jurídico da educação inclusiva. Presidência do Conselho de Ministros. Diário da República, n. ${ }^{\circ}$ 129/2018, Série I, de 6 de julho de 2018a.

PORTUGAL. Decreto-Lei n. ${ }^{\circ}$ 55/2018, de 6 de julho de 2018. Estabelece o currículo dos ensinos básico e secundário e os princípios orientadores da avaliação das aprendizagens. Presidência do Conselho de Ministro. Diário da República, n. ${ }^{\circ}$ 129/2018, Série I, de 6 de julho de 2018b

PORTUGAL. Despacho n. ${ }^{\circ}$ 6478/2017, de 26 de julho de 2017. Homologa o perfil dos alunos à saída da escolaridade obrigatória. Educação - Gabinete do Secretário de Estado da Educação. Diário da República,

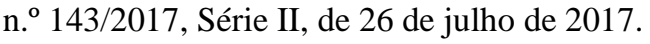

PORTUGAL. Lei n. ${ }^{\circ}$ 46/86, de 14 de outubro de 1986. A Assembleia da República decreta, nos termos da alínea d) do artigo 164. ${ }^{\circ}$ e da alínea e) do artigo 167. ${ }^{\circ}$ da Constituição a Lei de Bases do sistema Educativo. Diário da República, n. ${ }^{\circ}$ 237/1986, Série I, de 14 de outubro de 1986.

PORTUGAL. Lei n. ${ }^{\circ}$ 85/2009, de 27 de Agosto de 2009. Estabelece o regime da escolaridade obrigatória para as crianças e jovens que se encontram em idade escolar e consagra a universalidade da educação pré-escolar para as crianças a partir dos 5 anos de idade. Diário da República, 1. a série, n. ${ }^{\circ} 166$, de 27 de agosto de 2009.

PRIESTLEY, M.; BIESTA, G.; ROBINSON, S. Teacher agency: what is it and why does it matter?. In: KNEYBER, R.; EVERS, J. (eds.). Flip the system: changing education from the bottom up. London: Routledge, 2015. p. 134-148.

PRIESTLEY, M.; BIESTA, G.; ROBINSON, S. Teachers as agents of charge: teacher agency and emerging models of curriculum. In: PRIESTLEY M.; BIESTA, G. (eds.). Reiventing the curriculum: new trends in curriculum police and practice. London: Bloomsbury Academic, 2013. p. 187-206.

RAUPP, F. M.; BEUREN, I. M. Metodologia da pesquisa aplicável às ciências sociais. In: BEUREN, I. M. (ed.). Como elaborar trabalhos monográficos em contabilidade: teoria e prática. São Paulo: Atlas, 2006. p. 76-97.

REIS, I. Governança e regulação da educação: perspetivas e conceitos. Educação, Sociedade \& Culturas, Porto, n. 39, p. 101-118, 2013.

ROBERTSON, S. L.; DALE, R. Towards a “critical cultural political economy” account of the globalising of education. Journal Globalisation, Societies and Education, v. 13, n.1, 149-170, 2014.

RODRIGUES, D. Os desafios da equidade e da inclusão na formação de professores. In: ARMSTRONG, F.; RODRIGUES, D. (orgs.). A inclusão nas escolas. Lisboa: Fundação Francisco Manuel dos Santos, 2014. p. 69-101.

Roldão, M. C.; Almeida, S. de (2018). Curriculum contextualization in a network of portuguese schools: a promise or a missed opportunity? Estudos em Avaliação Educacional, (29)70, 8-45. Doi: http://dx.doi.org/10.18222/eae. v0ix.4757

ROLDÃO, M. C. Diferenciação curricular revisitada: conceito, discurso e práxis. Coleção Currículo, Políticas e Práticas. Porto: Porto Editora, 2003. 64 p.

SELLES, S. E.; ANDRADE, E. P. Políticas curriculares e a subalternização do trabalho docente. Educação em Foco, Juiz de Fora, v. 21, n. 1, p. 39-64, 2016.

SOUSA, J. M. A regulação da profissionalidade docente em andamentos. In: FRAGA, N. (org.). O professor 
do século XXI em perspetiva comparada: transformações e desafios para a construção de sociedades sustentáveis. Funchal, Madeira: CIE-Uma, 2019. p. 70-84.

TRINDADE, R.; COSME, A. A diferenciação curricular e pedagógica como um desafio epistemológico. Cadernos de Pesquisa: Pensamento Educacional, v. 9, n. 23, p. 21-42, 2014. Disponível em: https://seer.utp.br/index.php/a/article/view/342

UNESCO. A guide for ensuring inclusion and equity in education. Paris: UNESCO, 2017.

UNESCO. Educação para todos: o imperativo da qualidade; relatório de monitoramento global, 2005. UNESCO, 2004. Disponível em: https://unesdoc.unesco.org/ark:/48223/pf0000139079

UNESCO. Education 2030: Incheon declaration and framework for action towards inclusive and equitable quality education and lifelong learning for all. Incheon, Republic of Korea: UNESCO, 2015. Disponível em: https://iite.unesco.org/publications/education-2030-incheon-declaration-framework-action-towardsinclusive-equitable-quality-education-lifelong-learning/

UNESCO. Inclusive education: the way of the future. International Conference on Education, 48th session. Geneva: UNESCO, $2008 . \quad$ Disponível http://www.ibe.unesco.org/fileadmin/user_upload/Policy_Dialogue/48th_ICE/CONFINTED_483_English.pdf

UNESCO. Policy guidelines on inclusion in education. Paris: UNESCO, 2009. Disponível em: http://www.ibe.unesco.org/fileadmin/user_upload/Policy_Dialogue/48th_ICE/IE_policy_guidelines_draft. pdf

VAN DER HEIJDEN, H. R. M. et al. Characteristics of teachers as change agents. Teachers and Teaching: Theory and Practice, v. 21, n. 6, p. 681-699, 2015. DOI 10.1080/13540602.2015.1044328. Disponível em: https://doi.org/10.1080/13540602.2015.1044328

VELLOSO, L.; GRANJA, T. Práticas docentes e políticas curriculares: implicações no currículo em diferentes contextos escolares. Currículo Sem Fronteiras, v. 16, n. 2, p. 208-224, maio/ago. 2016. Disponível em: http://www.curriculosemfronteiras.org/vol16iss2articles/velloso-granja.htm

\section{Correspondência}

Preciosa Fernandes: Doutora em Ciências da Educação, professora da Faculdade de Psicologia e de Ciências da Educação da Universidade do Porto (FPCEUP) e investigadora do Centro de Investigação e Intervenção Educativas (CIIE) - sendo cocoordenadora da Comunidade Prática de Investigação: Currículo, Avaliação, Formação e Tecnologias Educativas (CAFTe) deste centro de investigação.

E-mail: preciosa@fpce.up.pt

Orcid: https://orcid.org/0000-0002-4318-3308

Paulo Marinho: Doutor em Ciências da Educação, Investigador do Centro de Investigação e Intervenção Educativas (CIIE) da Faculdade de Psicologia e de Ciências da Educação da Universidade do Porto (FPCEUP), Portugal e professor colaborador no Programa de Pós Graduação em Educação na Universidade Federal de Alagoas (UFAL), Brasil. Membro da Comunidade de Prática de Investigação Currículo, Avaliação, Formação e Tecnologias Educativas (CAFTe/CIIE/FPCEUP).

E-mail: pmtmarinho@fpce.up.pt

Orcid: https://orcid.org/0000-0003-4898-2982 
Texto publicado em Currículo sem Fronteiras com autorização dos autores. 